\title{
For Sport Journalists to Count and Report Major Championships in Golf: Per Coherent Definition and Conventional Classification, Nicklaus Has 20 Majors
}

\author{
John F. Gaski \\ University of Notre Dame
}

\begin{abstract}
Over the past 3 decades or so, some variation and revision have been introduced into the recording, reporting, and interpretation of the prime historical benchmark of individual golf achievement: number of established major tournaments won. In the interest of accuracy, consistency, and even equity, some analytic recordkeeping suggestions are proffered here, based on coherence and logic, toward presenting the history of golf's major championships in the fairest possible way. Idiosyncrasies of that historical sequence mean that the resolution is not obvious and more taxonomic work remains to be done. However, acceptance of the principles and conventions proposed herein may move the golf history culture and even basic golf chronicling closer to advantageous closure. One competitive implication of this reanalysis applies, significantly, to the total of "majors" won by historical greats Jack Nicklaus, Bobby Jones, and Tiger Woods.
\end{abstract}

Keywords: championship golf, golf history, golf taxonomy, Jack Nicklaus, sport taxonomy

Not so long ago, it was widely understood and publicly recognized that golfer Jack Nicklaus had won 20 major championships in his sport: 18 professional majors along with two U.S. Amateur titles. Golf scribes used to refer to his "20 majors," with the obligatory "18 pro majors" a common parenthetical adjunct or postscript. Then, over time, maybe because of (a) fallible human memory aggregating into mass knowledge discrepancy, (b) generational succession by younger sportswriters without first-hand connection to the focal events, or (c) the natural tendency to simplify and avoid nuance for convenience, the journalistic notation would typically become abbreviated to "18 majors." A profession that faces frequent deadline pressure would tend to gravitate toward any available simplifying strategy in written (or oratorical) composition, an occupational hazard surely familiar to most readers.

The author (jgaski@nd.edu) is with the Dept. of Marketing, University of Notre Dame, Notre Dame, IN, USA. 
Actually, considerable credit is due to those in the golf-reporting businessapparently many, even a majority in the recent past-who faced up to the nuance and reasonably credited Jack Nicklaus with 20 major titles won, including the two highly prestigious amateur championships (Ferguson, 2013). It was not so nuanced after all. But then standard reporting practice mutated away from historical custom and accuracy. In addition to the above hypotheses, the speculative social psychology seems straightforward enough: fashion behavior or "groupthink" evolving into dominant neo-custom.

So, the golf world now finds itself in a period of revisionist history when simplism eclipses tradition, stability, and reportorial consistency. Always appending the extra "20 majors" expression to " 18 pro majors" is understandably a cumbersome stylistic nuisance for overburdened golf writers, but they could just as easily report the " 20 " number and omit the " 18 " to streamline, so more diagnosis is needed.

There is ample reason to believe that the present revisionist period may be transitory, and that history-oriented golf journalists can return to their previous usage norm-for posterity, epistemological coherence, and Mr. Nicklaus's incomparable legacy. What kind of reason? First, as noted, the golf news media demonstrated a capability in the relatively recent past to perceive the nuanced 20 total as the most reasonable and fair number to attach to the famed Golden Bear's major win record. This shows that they have been open to the idea of the " 20 " convention. If the underlying proposition is valid-argued here that it issurely the golf reporting fraternity and their successors may come to retrieve lost custom and summon the capacity to see things the same way again. Not that they automatically will, but they could. In other words, the media have shown an ability to adopt a certain perspective, at least sometimes. This establishes a necessary condition for potential acceptance of the advocated interpretation.

Beyond that and building upon this precondition, the most substantive justification for counting the U.S. Amateur as a true major championship retrospectively for Mr. Nicklaus's competitive time relates to the preceding and remains the same now as before, to wit: That particular tournament-the "U.S. Am," colloquially_—was not only recognized as a major by the golf establishment, but also recognized as such contemporaneously. This means the U.S. Amateur received its "major title" imprimatur from expert observers who had the closest historical vantage point. All one need do is inspect press accounts from that era (e.g., Jenkins, 1973; Strode, 1973) to discern that when Jack Nicklaus was celebrated for first surpassing the great Bobby Jones's major win total of 13 (including Jones's U.S. and British Amateur championships!), the U.S. Am was also included in the accounting for Nicklaus. (See Table 1 for detail, including the record for Mr. Jones, the top golfer of the 1920s and early 1930s, and his contemporary, Walter Hagen, recognized as the first genuine professional golfer in the sense of competitive golf as primary occupation.)

To punctuate, the reason Bobby Jones's record is permitted to include the two types of amateur wins among his majors is that they were considered such in his time. The same is true for the era when Jack Nicklaus was winning the U.S. Amateur (This Day in History, 2010). Of course, this is also true for Arnold Palmer (and many others of the Jones-Nicklaus interregnum), so add one major to Arnie's total as well.

This sensibly grounded argument is likely to prevail over the long term because it is more coherent than the opposing perspective, which is seen to be 
Table 1 Major Golf Championships Won: Historical Leaders ${ }^{a}$

\begin{tabular}{lcccc}
\hline Event & Jack Nicklaus & Bobby Jones & Tiger Woods & Walter Hagen \\
\hline U.S. Amateur & 2 & 5 & 3 & - \\
British Amateur & - & 1 & - & - \\
Masters & 6 & - & 5 & - \\
U.S. Open & 4 & 4 & 3 & 2 \\
British Open & 3 & 3 & 3 & 4 \\
PGA & 5 & - & 4 & 5 \\
Total & 20 & 13 & 18 & $11^{\mathrm{b}}$ \\
\hline
\end{tabular}

Note. PGA = Professional Golfers' Association.

${ }^{a}$ If counting U.S./British Amateurs as majors. ${ }^{\mathrm{b}}$ Total would be 16 if counting wins in the former Western Open, considered a major during Hagen's competitive era (1912-1936).

erratic via incompatible results born of inconsistent application of criteria to different time periods. As Mr. Nicklaus himself once recalled the proto-inception of the capricious change in counting customs, "I was probably at 17 or 18 majors [won, as of a late career stage, c. 1978-80], including the Amateurs, and all of a sudden I had 15 or 16! 'What happened here?' All of a sudden it became 'professional' majors" (Ferguson, 2013). This marked the beginning of a revised "major" definition and usage, if not yet a consensus. Over the full sweep of future history, however, good logical coinage would tend to drive out the bad. (Yes, there is an arcane economic law that underlies this proposition.) So, it is reasonable to anticipate an ultimate reversion to the 20-major popular acceptance for Nicklaus.

Apropos of Bobby Jones again, ignoring or discounting the two Nicklaus U.S. Amateur wins with respect to his major total is not identical but very similar to a hypothetical attempt to retroactively subtract from the Jones list of majors because of arbitrary reclassification decades later. (It is not always hypothetical. Some website sources, including those that should know better, do crudely downgrade Jones's total to seven from 13; e.g., World Golf Hall of Fame, 2020). There is no dispute that the U.S. and British Amateurs were regarded as major championships in Mr. Jones's time, but they also were when Jack Nicklaus won two of them (the U.S. version) in 1959 and 1961. As late as 1981 and 2008, two premier golf historian-journalists confirmed this status and Mr. Nicklaus's major count of 20 (Feinstein, 1981; Jenkins, 2008). An underlying reason for continued recognition of the U.S. and British Amateurs as major tournaments through Nicklaus's amateur career was that many top players would remain amateur throughout their lives then. (Nicklaus, himself, nearly did the same by aspiring to become a pharmacist and even pursuing that college academic major.)

\section{Taxonomic Interjection}

What of a constitutive or operational definition of major championship per se for men's golf, the sine qua non of meaningful classification in general (Bunge, 1967, p. 75; Rudner, 1966, pp. 14-22)? It is not clear if golf organizations or culture have 
ever approached formality or rigor in this regard, including the iconic Bobby Jones, who described "majors" as simply different from other tournaments (Shedloski, 2019, p. 1). Rather, generally accepted designation appears to hinge upon a galvanized consensus that certain ones are, and others are not, the former being much more important and prestigious. (Women's professional golf, on the other hand, has devoted formal effort to identifying and ratifying a particular set of five tournaments as the major events of the Ladies Professional Golf Association tour, even amending the designated set on various occasions over the years. Still, the decision ultimately depends on group subjective judgment.)

In further search of a more concrete definition of major championship, what of the greater psychological pressure involved, which the competitors confirm? How should that condition be factored in, albeit a less tangible and more personal trait itself? This issue, however, should be self-regulating. Without the competitive pressure of a major, as perceived and experienced by the players themselves, a golf event never would have gained consensus status as major among those who participate. Absence of major-level pressure would be a definitional disqualifier, in other words, and an event so lacking would not become perceptually elevated to major status by consensus of those most directly engaged. Likewise, if Jack Nicklaus and others of his era felt major-type pressure while participating in U.S (or British) Amateurs, the events pass at least a threshold qualification.

An objective definition of a men's golf "major" would be taxonomically desirable, of course, and one is at hand: whatever a concurrent consensus thinks is a major. It is the consensus perception that seems to dictate-which affirms the U.S./ British Amateurs historically. (Ironically, this objective definition is one that incorporates group subjectivity as underlying basis.) Yet the question remains whether a given consensus is adequately grounded or cogent, hence the present rationale development and discussion. It is also possible for a consensus to change based on evidence and argumentation, so further probe of fundamental basis can be productive.

\section{Oblique Aspects}

For another independent perspective, tantamount to one respectable if not unbiased vote for the numerical resolution argued here, some may recall that the Hall of Fame pro Lanny Wadkins, active on the PGA tour between the 1970s and 1990s, would correct anyone who identified his record as including only one major. No, paraphrasing Wadkins, his major total is two, including the 1970 U.S. Amateur. This establishes further, credible, cognition-based recognition of that tournament as a legitimate major title even after Mr. Nicklaus's amateur career.

To be sure, the fact that Mr. Wadkins had to reply to others who perceived not two but one major for him also manifests a difference of opinion about how to count golf majors even then. Thus, in the interest of balance, we should acknowledge that there is a contrary argument. There are indeed reasons not to designate the U.S. Amateur as a true major golf championship even in or near Jack Nicklaus's time. Supreme among the reasons might be quality of the field of competitors. With all professional players excluded by definition, how can the U.S., British, or any amateur event qualify for recognition as a major championship? 
Fair enough. In reply, though, there also is much variance in field quality among the professional majors. The difference in quality between the best and worst major pro tournament competitor fields (PGA and Masters, respectively, most would agree) might even approach the spread between the weakest pro tournament field and that of the U.S. or British Amateur, especially in the Jones -Nicklaus eras, which featured the custom of top-quality career amateurs. Might, that is. But if the U.S. (or British) "Am" is to be disrespected for excluding professional contestants, why not also the PGA Championship (or Players Championship, another high-profile event) for excluding the best amateur golfers? How many total majors would Bobby Jones have won if allowed to play in the PGA during his prime? That is a telling rhetorical question. Given Jones's record of beating the pros to win the U.S. Open four times from 1923 to 1930, a logical rough estimate would be another four added to his ledger, for 17 total majors.

One professional nonmajor, in fact (the Players), is widely considered to have a stronger field than any of the Big Four pro majors because only pro tour players are allowed to participate. So, field quality is not everything in defining what is and is not a major. Prestige and tradition-two more perceptual components-are others. On that score, the U.S. Amateur rates well.

Moreover, the quality of venue can be a contributory factor in attaching "major" standing. The U.S. Am's venue history surpasses the PGA Championship's selection of courses on that dimension over extended historical time periods. Older readers may recall when the PGA was chronically embarrassed by its flagship tournament's long-term pattern of second-rate sites, which basically prevailed almost uniformly prior to 1975 .

Now, for a pertinent digression on "the Players" championship, resolution of the Nicklaus 20-versus-18 issue may not even be the last word in perfecting the historical accounting of major golf championships. For many years, the PGA tour's Players Championship has been informally known as the "fifth major." Polling of tour members confirms that some, although a minority, rank the event ahead of the PGA Championship itself in prestige (Schupak, 2019). Perhaps the most potent factor supporting the Players' case as a major in golf's pantheon is that, as of 2014, the main criterion for selection to the World Golf Hall of Fame (in the male category) has been changed from victory in at least two traditional majors to two wins from among those four or the Players. This, by definition, confers special status on the Players tournament.

For these reasons collectively, many expect "the Players" to be formally recognized as pro golf's fifth major ultimately (or seventh major overall, if the U.S. and British Amateurs are counted?). Other tours, such as the Ladies Professional Golf Association and PGA Champions (seniors), do have more than four established majors.

So, what happens in terms of historical record keeping if and when the Players become accepted as a real major? All past winners get to add a major to their résumés? Not likely. What is more likely is that some will. It will be for sport historians and the golf culture to determine at what point in its history the Players genuinely had graduated to major status. (This paper does not endeavor to resolve all classification problems of golf metaphysics.) Nevertheless, one possible objective approach to an answer is this: When the tournament changed its name from the "TPC" (Tournament Players Championship) to "the Players," it symbolized elevation of prestige to the major level. Or, a bit more generously, the 
transition of the brand name from "TPD" (Tournament Players Division) to TPC very early in the event's history could be used to signify the watershed demarcation. (Depending on when or whether such recognition occurs, and where the temporal dividing line for the Players would be placed, Jack Nicklaus could belatedly be awarded up to three more majors! But, again, that is not likely.)

The same retrospective analysis needs to be done for the U.S. and British Amateurs to provide fairness and justice to Mr. Nicklaus and other past winners. The forecast here is that consensus official judgment of when the U.S. Amateur dropped out of major status, if it ever did, will be determined as sometime after the Nicklaus active period, not between the Jones and Nicklaus eras. Support for this expectation can be bolstered by checking old clippings or searching online (see, e.g., This Day in History, 2010 or Jenkins, 1973). The U.S. Open and U.S. Amateur during the period of Nicklaus's early career were characteristically referenced co-equally as the "National Open" and "National Amateur." Contemporary endorsement carries extra weight, and revisionist history is usually bested by the original. Toward valid epistemology, the role for current and future golf historians will be to impose justice retroactively by according rightful value to past observers and recorders of their own contemporaneous events. (This is not a recommendation for the "arbitrary reclassification" decried earlier, but a nonarbitrary classification based on valid criteria and history.) It is objective fact that the U.S. Amateur was generally considered a golf major when Jack Nicklaus competed and won, if not later, or there would have been no media recognition of his surpassing Bobby Jones's major total in 1973. Rightfully, the case should be closed-except for a possibly helpful corollary:

There could even be interplay between retrospective assessment of the Players and U.S. Amateur. A possible objective answer for when the Amateur was/was not, or should be/should not be, a major: If year $x$ were to be decided as the demarcation for the Players' ascension to major status, then year $x$ could also be the year the U.S. (and/or British) Amateur is removed from the major category. A Solomonic justification for this correspondence would be avoidance of having surplus or excessive designated majors in a given era. A strong case could be made for completely independent reanalysis of Amateur/Players history qua possible major status, but a strong argument also attaches to a roster of select few "major" tournaments on the annual golf calendar. (Again, impact on eligibility for the World Golf Hall of Fame is a side effect, but an important issue in its own right. The most drastic implication of the remedial variants tendered herein would be that winners of multiple U.S. and/or British Amateurs gain the minimum qualification. Of 38 men in that category, 13 are already Hall of Fame inductees. Of 11 winners of both the U.S. Am and U.S. Open, nine are in the Hall.)

Begging indulgence, one additional classificatory question seems apt here, and perhaps unavoidable over the long term: With golf now an Olympic sport, will an Olympic gold medal in golf ever be considered a major championship or the equivalent? So we roil the cosmic equilibrium even more.

\section{Tiger, Too, and What Else?}

Does all this reappraisal leave the renowned Tiger Woods out of luck, unable to count three U.S. Am titles along with his 15 pro majors for 18 in total—so far? That answer is unknown, as of now. The prospective U.S. Am major-or-not temporal 
demarcation line suggested above might eventually be pre-Tiger or could be postTiger, but this decision is again for future historians a bit further removed, when more historical perspective is available. When that assessment finally is made, however, an important informational input will be how and what contemporaries thought. Even nonelderly readers will need no old clippings, footage, or references to know that during the early phase of Tiger's pro career and public life as a golf legend, it was still common for some media to treat his three U.S. Am wins as among his major championships. But is "some" enough? Regardless, our nearly proximate but somewhat removed temporal vantage point does not preclude us from also noticing that Jack Nicklaus's two U.S. Amateur titles were definitely regarded in their time as majors "on a par," so to speak, with professional majors of the same era.

So, to recap, the principles and conventions promised at the outset as analytic cornerstones in arriving at a "golf major" definition reduce to historical proximity, consistency, fidelity, and respect, along with the epistemological coherence referenced throughout. In short, if a golf event is recognized as a major in its own time, that is a convincing standard and very difficult and questionable to supersede retroactively-especially decades later by commentators without the benefit of first-hand relation to the pertinent phenomena or issues. Per the age-old scientific research axiom, primary data, in this case contemporaneous observation, take precedence over secondary data (that is, temporally remote observation or reports) in this history context.

Is a contradictory treatment of those future golf historians displayed here by deferring to their ultimate judgment about championship golf designation, while also favoring concurrency? To the contrary, it is more dualist. Long-term retrospective will and should be determinative because of the advantage of more comprehensive input, but it should be a retrospective very cautious about overriding contemporaneous valuation (i.e., giving appropriate weight to the assessment of proximate observers). A moderated, two-factor decision approach is advocated, essentially.

Admittedly, the argument adduced here is not perfect. Few things created by humans are, but I submit that the case for 20 generally accepted Jack Nicklaus major championships is much more cogent than the one for 18. That case is now rested-but there remains one tangential complication.

During pro golf's formative years, even into the 1940s and 1950s, several other tournaments were regarded as "major" in their time. Examples might include the Western Open and so-called World Championship of Golf (Jenkins, 1973, p. 19). To provide a more accurate history than the extant no-nuance version, golf historians will someday have to wrestle with the kind of major status review and demarcation issue described here for the U.S. (and British) Am and Players-but also for several other tournaments that once may have been of major stature but clearly are no more, or no longer even exist. That, however, is a task for another day, maybe another generation. Resolved for now, I suggest, is the 20-majors-forNicklaus issue, and this represents progress, even justice.

\section{Broader Parallels and Cross-Sport Insights}

Similar logic relying on the primacy of contemporaneous perspective and assessment can also be applied to taxonomic problems of the historical metrics in some 
other sports. (a) For example, needless ambiguity caused by different universities counting their own totals of national collegiate football championships in inconsistent ways because of different criteria (before the playoff era removed most ambiguity) could be resolved if all would accept the National Collegiate Athletic Association (NCAA) record book's comprehensive historical accounting (Gaski, 2011; National Collegiate Athletic Association, 2020, pp. 91-119). One curiosity caused by football-playing schools counting their national championships idiosyncratically instead of uniformly is that most schools tend to inflate their selfreported totals in excess of the quasi-official NCAA numbers. (For instance, the University of Alabama has been exposed for retroactively adding putative past years' championships not recognized by the NCAA to its reported total; Bachman, 2013.) The sports media then rely on and report this information as disseminated by university athletic departments - instead of taking it upon themselves to adjudicate which championships count, as we have seen done with golf major championship totals. Without an air-tight and generally accepted definition and taxonomy, neither process is optimal.

(b) For more frustration, a rhetorical question: Which team won the national championship in men's college basketball in 1938? No one seems to know, or care, because the NCAA tournament began in 1939. So, were there no annual national champions in that sport before 1939? There were, but determined by different methods such as retrospective judgmental award by the prominent Helms Athletic Foundation-which was widely considered rather "mythical," in the sport vernacular, as with the poll system in college football before the playoff era.

Aside from the subjective judgment method, the National Invitation Tournament was a true national championship and was more recognized as such than the rival NCAA event until around 1950. In counting up national titles won in men's basketball, therefore, some credit - even full credit - should be given to accomplishments of the pre-1939 period. (The NIT winner in 1938 was Temple University, a legitimate national champion, as were several subsequent NIT winners.) Likewise, Jack Nicklaus was an undisputed national champion via his National Amateur wins in 1959 and 1961. Or is the U.S. Amateur-U.S. Open distinction in golf analogous to the NCAA tournament-NBA championship in men's basketball, thereby reducing the relative stature of the former? No, the NCAA golf championship versus PGA championship would be the golf analog to the basketball comparison.

A potential corollary complication looms: In the far future, will past college football national championships we now recognize, but which occurred before the playoff era began in 1998, then be disregarded and, in effect, nullified and ignored, as with pre-NCAA tourney basketball? Such are the definitional demons released by insufficient attention to taxonomic fundamentals, whether in traditional philosophy or sport and its communication adjunct.

(c) More pertinent and comparable to golf, yet a contrary case, is tennis, an individual sport which also has a small set of tournaments it considers its majors: Wimbledon and the U.S., Australian, and French Opens. Unlike golf, though, tennis arrived at a consensus understanding on this point long ago (1925) and has seen no reason to deviate. The key dissimilarity is that, in golf, the Masters and PGA really were not regarded as major championships until well into their respective histories, supplanting the Western Open, which had been a recognized 
major. Therefore, as mentioned, the retrospective major-designating task for golf could be even more complex than the main focus already outlined, if any authoritative group would undertake it. (Again, all possible taxonomic reconciliation is not sought here, only that for a thematic selection of the most fundamental quandaries.)

The formality of some kind of official sanction would indeed be welcome nonetheless because unofficial custom has permitted loose-end lacunae to infect the metric heritage of men's golf. Women's golf, on the other hand, does not repress or discount its former major tournaments. Its official records still include victories in extinct major championships in the tabulation of individual golfer major totals. This approach could serve as a model for resolving the problems identified here.

\section{A Tangential Postscript and Extension}

Toward cleaning up a final, slightly intersecting semantic problem, if only the golf world would stop referring to the British Open as "the Open"! Might American golf reporters and observers in particular be subject to a manipulation gambit by those, apparently including Britain's Royal \& Ancient Golf Society, who wish to derogate the U.S. Open to their own benefit? To be consistent, as long as the U.S. Golf Association-sponsored open golf tournament is called the "U.S. Open," then the one conducted by the Royal \& Ancient should properly be called the " $R \& A$ Open," at least informally. Or, to propose an even more efficient option, just call it the "British Open," as it long had been known popularly. The R \& A should be reminded that their "Open" was an international afterthought for quite a few years—after Bobby Jones's time, not during-until more Americans began entering because of the emergence of jet air travel in the 1960s. Before that, the U.S. Open was "the Open" for most.

The R \& A should also dial back its tendentious "champion golfer of the year" rhetorical claim for the British Open winner. He is a champion, yes, but of one tournament. The event surely does rank considerably higher than the Quad Cities Open or Humana Classic in the golf hierarchy, but it is only one. This extra dose of hubris by the R \& A seems another transparent ploy to "one-up" the other majors-a device that may wax very tedious to the sophisticated and discerning golf audience.

Finally, what could be the connection between this $\mathrm{R} \& \mathrm{~A}$ issue and the matter of rightful number of majors for Jack Nicklaus? The nexus is this: When historical recording is involved, accurate definition and language are important to prevent misrepresentation or outright appropriation of history, even golf history. Based on the details and subtleties addressed here, some of golf's linguistic and taxonomic conventions need to be reviewed. The two targeted here both relate to golf's supreme metric, major championships, along with their accurate portrayal and derived perception for posterity. This subject matter should be important to all who revere the game of golf and its heritage.

\section{Acknowledgments}

The author thanks Jack and Barbara Nicklaus and golf journalist John Fineran for their generous time and consideration. 


\section{References}

Bachman, R. (2013, January 3). Who's no. 1 in college football is a contested issue. The Wall Street Journal, A1, A5.

Bunge, M. (1967). Scientific research I: The search for system. Springer-Verlag.

Feinstein, J. (1981, June 17). The mystique and glory of golf's 'majors.' The Washington Post. https://washingtonpost.com/archive/sports/1981/06/17/the-mystique-and-gloryof-golfs-majors/750e1a92-1815-4f83-b148-85491b3df94f/

Ferguson, D. (2013, April 23). Notes: Why is Jack's major total 18, not 20? Golf Channel. https://golfchannel.com/news/notes-why-jack-nicklaus-major-championshiptotal-18-and-not-20\#: :text=Nicklaus\%20recalls\%20Browning\%20making\%20a,times\% 20from\%201994\%20to\%201996

Gaski, J.F. (2011). Counting college football national championships: A streamlined answer. Sporting Traditions, 28(2), 1-12.

Jenkins, D. (1973, August 20). Jack goes one up on a legend. Sports Illustrated, 39, 18-19. https://www.si.com/vault/1973/08/20/615242/jack-goes-one-up-on-a-legend

Jenkins, D. (2008, June). All by himself. Golf Digest, 59(6). https://golfdigest.com/story/ 0610pgareport

National Collegiate Athletic Association. (2020). Annual team champions. In NCAA football bowl subdivision records (pp. 115-121). https://fs.ncaa.org/Docs/stats/ football_records/2020/FBS.pdf

Rudner, R.S. (1966). Philosophy of social science. Prentice-Hall.

Schupak, A. (2019, October). No filter! Players sound off on Brooks v. Rory, Tiger, Bryson, hot drivers, much more. Golf Magazine, 61(10). https://golf.com/news/features/ anonymous-pro-survey-pga-tour-tiger-trump-cheating/

Shedloski, D. (2019). What does it take to win a major championship? Kingdom of Golf, 46. https://kingdom.golf/golf/winning-a-major-championship/

Strode, G. (1973, August 13). Nicklaus surpasses Jones record with PGA victory. Farmington Daily Times, 11. https://newspaperarchive.com/farmington-daily-times-aug-131973-p-11/

This Day in History. (2010, February 9). Nicklaus sets title record. https://www.history.com/ this-day-in-history/nicklaus-sets-title-record

World Golf Hall of Fame. (2020). Bobby Jones. Members. https://worldgolfhalloffame.org/ bobby-jones/ 